\title{
INDEX OF MICROVASCULAR RESISTANCE TO ASSESS THE EFFECT OF ROSUVASTATIN ON MICROVASCULAR FUNCTION IN WOMEN WITH CHEST PAIN AND NO OBSTRUCTIVE CORONARY ARTERY DISEASE. A DOUBLE-BLIND RANDOMIZED STUDY
}

\begin{tabular}{|r|l|}
\hline Journal: & Catheterization and Cardiovascular Interventions \\
\hline Manuscript ID & CCI-18-0618.R2 \\
\hline Wiley - Manuscript type: & Original Studies \\
\hline Keywords: & $\begin{array}{l}\text { CORB - Coronary Blood Flow/Physiology/Microvascular Function, GEND - } \\
\text { Gender, Outcomes/Studies, MICR - Microcirculation, LIP - Lipids }\end{array}$ \\
\hline \multicolumn{2}{|l}{} \\
\hline
\end{tabular}

\section{SCHOLARONE ${ }^{m}$ \\ Manuscripts}




\title{
INDEX OF MICROVASCULAR RESISTANCE TO ASSESS THE EFFECT OF ROSUVASTATIN ON MICROVASCULAR FUNCTION IN WOMEN WITH CHEST PAIN AND NO OBSTRUCTIVE CORONARY ARTERY DISEASE. A DOUBLE-BLIND RANDOMIZED STUDY
}

\author{
Ole Geir Solberg MD PhD ${ }^{1}$, Knut Stavem MD PhD MPH²,3, Asgrimur Ragnarsson MD ${ }^{5}$, \\ Jan-Otto Beitnes MD PhD ${ }^{1}$, Rita Skårdal RN MSc${ }^{1}$, Ingebjørg Seljeflot $\mathrm{PhD}^{2,6}$, Thor Ueland \\ $\mathrm{PhD}^{2,7,8}$, Pål Aukrust MD PhD $2,8,9$, Lars Gullestad MD PhD ${ }^{1,2,10}$, Lars Aaberge MD PhD ${ }^{1}$.
}

${ }^{1}$ Department of Cardiology, Oslo University Hospital, Rikshospitalet, Oslo, Norway.

${ }^{2}$ Institute of Clinical Medicine, University of Oslo, Faculty of Medicine, Oslo, Norway.

${ }^{3}$ Department of Pulmonary Medicine, Akershus University Hospital, Lørenskog, Norway.

${ }^{4}$ Department of Health Services Research, Akershus University Hospital, Lørenskog, Norway.

${ }^{5}$ Department of Radiology, Oslo University Hospital, Rikshospitalet, Oslo, Norway.

${ }^{6}$ Center for Clinical Heart Research, Department of Cardiology, Oslo University Hospital, Ullevål, Oslo, Norway.

${ }^{7}$ K.G. Jebsen TREC, University of Tromsø, Tromsø, Norway.

${ }^{8}$ Research Institute of Internal Medicine, Oslo University Hospital, Rikshospitalet, Oslo, Norway.

${ }^{9}$ Section of Clinical Immunology and Infectious Diseases, Oslo University Hospital, Rikshospitalet, Oslo, Norway.

${ }^{10}$ K.G. Jebsen Cardiac Research Centre and Centre for Heart Failure Research, Faculty of Medicine, Oslo University Hospital, Oslo, Norway.

Corresponding author: Ole Geir Solberg, Oslo University Hospital, Rikshospitalet, Department of Cardiology, POB 4950 Nydalen, 0424 Oslo, Norway.

E-mail: geosolb@online.no; ogsolber@ous-hf.no

Phone: $\quad+47-23070000$

Fax: $\quad+47-23071950$

Keywords: microvascular angina; index of microvascular resistance; statin; rosuvastatin; health-related quality of life; health status. 
Word count: 4360

The study was performed at Oslo University Hospital, Rikshospitalet, Department of Cardiology, POB 4950 Nydalen, 0424 Oslo, Norway.

Running head: Effect of rosuvastatin assessed with IMR 


\begin{abstract}
Introduction: Many women undergoing coronary angiography for chest pain have no or only minimal coronary artery disease (CAD). However, despite the lack of obstructive CAD, they still have an increased risk of major adverse cardiovascular events. Pleiotropic effects of statins may influence microvascular function, but if statins improve microvascular function in unselected chest pain patients is not well studied. This study assessed microvascular function by using the thermodilution-derived test "the index of microvascular resistance" (IMR) with the aim of determining the (i) IMR level in women with chest pain and non-obstructive CAD and if (ii) IMR is modified by high-dose statin treatment in these patients. Additional objectives were to identify the influence of statins on the health status as assessed with generic health questionnaires and on biomarkers of endothelial activation.
\end{abstract}

Materials and Methods: The study was a randomized, double-blind, single-centre trial comparing 6 months of rosuvastatin treatment with placebo. In total, 66 women without obstructive CAD were included. Mean age was 52.7 years and 55.5 years in the placebo and rosuvastatin group, respectively. Microvascular function was assessed using the IMR, health status was assessed using the SF-36 and EQ-5D questionnaires, and biochemical values were assessed at baseline and 6 months later.

Results and Conclusions: In the placebo group IMR was 14.6 (SD 5.7) at baseline and 14.4 (SD 6.5) at follow-up. In the rosuvastatin group IMR was 16.5 (SD 7.5) at baseline and 14.2 (SD 5.8) at follow-up. IMR did not differ significantly between the two study groups at follow-up controlled for preintervention values. C-reactive protein (CRP) was comparable between the groups at baseline, while at follow-up CRP was significantly lower in the rosuvastatin group compared to placebo $[0.6( \pm 0.5) \mathrm{mg} / \mathrm{L}$ vs $2.6( \pm 3.0) \mathrm{mg} / \mathrm{L} ; \mathrm{p}=0.002]$. Whereas rosuvastatin treatment for 6 months attenuated CRP levels, it did not improve 
microvascular function as assessed by IMR. (Clinical Trials.gov NCT 01582165. EUDRACT (2011-002630-39.3tcAZ) 


\section{INTRODUCTION}

Many women undergoing coronary angiography for chest pain have no or only minimal coronary artery disease (CAD) ${ }^{1,2}$. However, despite the lack of obstructive CAD, they still have an increased risk of major adverse cardiovascular events such as cardiovascular mortality, hospitalization for myocardial infarction, heart failure and stroke ${ }^{2}$. Furthermore, persistent chest pain predicts cardiovascular adverse events ${ }^{3}$ and is associated with impaired health status ${ }^{4,5}$. The ischaemic symptoms in non-obstructive CAD have diverse aetiologies ${ }^{6}$. In addition to their cholesterol-lowering effect, statins influence microvascular function and endothelial activation (which constitute part of their pleiotropic effects) ${ }^{7-13}$, at least partly involving increased bioavailability of nitric oxide, decreased levels of endothelin-1 and reduced oxidative stress ${ }^{14}$. However, the statin effect on microvascular function in general in patients with chest pain and no obstructive coronary artery disease, is not well studied. The extent to which statins also exert endothelium-independent effects that may improve ischaemic symptoms in non-obstructive CAD remains unclear. Because the coronary microcirculation cannot be directly visualized, it needs to be assessed using indirect methods. One such method, available during a routine diagnostic coronary angiography, is the thermodilution-derived functional test, the index of microvascular resistance (IMR) ${ }^{15}$, which primarily explores endothelium-independent coronary microvascular dysfunction (CMD) via the intravenous infusion of adenosine.

The objectives of the present study were to determine the (i) IMR level in women with chest pain and non-obstructive CAD and if (ii) IMR is modified by high-dose statin treatment in these patients. Additional objectives were to identify how statins influence the health status as assessed with generic health questionnaires and biomarkers of endothelial activation. The study therefore aimed to study a broad spectrum of patients with chest pain without 
significant $\mathrm{CAD}$ and was not limited to those with microvascular dysfunction testing the hypothesis that statins generally improve microvascular function, and that any improvement in microvascular function would improve the end-point included in the study.

\section{MATERIALS AND METHODS}

\section{Study design}

This study was a randomized, double-blind, single-centre trial comparing 6 months of rosuvastatin treatment with placebo. Eligible women who had been referred to receive coronary angiography from 2012 to 2016 were recruited for inclusion in the study. The study protocol was approved by the South East Department of the Norwegian Regional Committee for Medical and Health Research Ethics (Approval code 2011/1600) and the local review board of the hospital. The study was conducted in compliance with Good Clinical Practice and with the tenets of the Declaration of Helsinki and was registered at ClinicalTrials.gov (NCT 01582165) and EUDRACT (2011-002630-39.3tcAZ).

\section{Study design and participants}

Oslo University Hospital, Rikshospitalet is a tertiary referral centre in Oslo, Norway for interventional cardiology. Female patients aged 30-70 years with suspected ischaemic chest pain and unknown coronary anatomy who were referred for coronary angiography as part of a diagnostic workup were eligible for inclusion in this study. In total, 81 women were screened. Coronary angiography revealed that 13 had obstructive CAD [defined as a fractional flow reserve (FFR) of $\leq 0.80$ or at least 1 occluded major coronary artery], 1 had diffuse atheromatosis and other reasons for statin therapy, and 1 was unable to comply with the study 
protocol due to panic disorder (Figure 1). Hence, 66 women with angina pectoris and normal or near-normal coronary angiograms with FFR exceeding the ischaemic threshold of 0.80 were included in the study (Figure 1). Positive or equivocal findings in bicycle ergometry were a prerequisite for inclusion. Exclusion criteria were coronary artery stenosis $\geq 33 \%$ in any epicardial vessel, pregnancy or nursing, childbearing potential and not using contraception, short life expectancy, uncontrolled endocrine disease, uncontrolled arterial hypertension, structural heart disease, significant mental disorder including dementia or inability to comply with the protocol.

After diagnostic left-heart catheterization including a coronary physiology assessment, the patients were randomly assigned to 6 months of treatment with rosuvastatin or placebo in a double-blinded fashion. Written informed consent was obtained from all patients prior to performing heart catheterization.

\section{Randomization and study drugs}

The randomization scheme (in a 1:1 ratio for treatment:placebo) was generated by the Centre for Biostatistics and Epidemiology at the hospital using a computerized procedure. Numbered boxes with the placebo or the treatment drug (according to the randomization scheme) were consecutively dispatched to the included patients. The helpers who prepared the boxes were not otherwise involved in the study. Identical placebo and treatment-drug tablets were supplied free-of-charge by Astra Zeneca UK. The daily starting dose was $20 \mathrm{mg}$ of rosuvastatin or the matching placebo. The same dose was given throughout the study.

\section{Echocardiography}

Transthoracic images were obtained from parasternal and apical positions recording standard parasternal imaging planes using high-end echocardiography scanners (Vivid 7 $^{\mathrm{TM}}$ or E9 ${ }^{\mathrm{TM}}$, GE Vingmed, Horten, Norway) according to current recommendations ${ }^{16}$. Conventional 
greyscale cineloops as well as tissue Doppler loops and blood flow velocities as measured using Doppler flowmetry were recorded. Data for at least three consecutive representative heart beats were obtained and stored on a server.

\section{Heart catheterization and coronary physiological assessments}

Left-heart catheterization was performed mostly using a transradial approach with a 6-French arterial sheath and 6-French diagnostic and guiding catheters, and only in exceptional circumstances via the femoral artery. At the start of the procedure, 5,000 $\mathrm{U}$ of heparin, $2.5 \mathrm{mg}$ of verapamil and $200 \mu \mathrm{g}$ of glyceryl trinitrate were administered intra-arterially. Coronary physiological measurements were made with a pressure- and thermistor-equipped guide wire (PressureWire Certus, St. Jude Medical, St. Paul, MN, USA), with $200 \mu$ g of glyceryl trinitrate administered via an intracoronary injection before making the measurements. Hyperaemia was obtained by the intravenous infusion of $140 \mu \mathrm{g} / \mathrm{kg} / \mathrm{min}$ adenosine. The procedure has been reported previously in detail ${ }^{17}$. In short, the aortic pressure $\left(P_{\mathrm{a}}\right)$ and distal coronary artery pressure $\left(P_{\mathrm{d}}\right)$ were measured in the presence and absence of hyperaemia. Both at baseline and during hyperaemia, $3-4 \mathrm{~mL}$ of room-temperature saline was injected into the investigated coronary artery, and the resting transit time $\left(T_{\mathrm{mnr}}\right)$ and hyperaemic transit time $\left(T_{\mathrm{mnh}}\right)$ were recorded. The coronary physiological indices were calculated as follows:

$\mathrm{FFR}=P_{\mathrm{d}} / P_{\mathrm{a}}(\leq 0.80$ indicates myocardial ischaemia due to epicardial CAD $)$.

$\mathrm{IMR}=P_{\mathrm{d}} \times T_{\mathrm{mnh}}[$ no definite threshold has been established, but $>20.8 \mathrm{mmHg} \cdot \mathrm{s}$ was used to detect CMD based on a previous study in our hospital ${ }^{17}$ ].

$\mathrm{CFR}=T_{\mathrm{mnr}} / T_{\mathrm{mnh}}$ (coronary flow reserve, where $<2.5$ or $<2.0$ is considered pathological). FFR was averaged over three heart beats for which its value was the lowest. 
The continuous equalization of pressures was confirmed at the end of the procedure by repositioning the pressure wire in the ostium of the vessel. Care was taken to ensure that the coronary physiological measurements were made in approximately the same position in the vessel during the second heart catheterization procedure.

\section{Health status}

Health status was assessed using version 1.2 of the generic 36-item Short Form Health Survey (SF-36) and the 5-dimension EuroQol (EQ-5D) questionnaires at baseline and 6 months later. SF-36 assesses the following eight dimensions of health during the previous 4 weeks: Physical functioning, physical role limitations, bodily pain, general perceived health, vitality, social functioning, emotional role limitations and mental health ${ }^{18}$. The SF-36 score ranges from 0 to 100, with higher scores indicating better health. The dimension scores were aggregated to provide two summary scales - the physical component summary (PCS) and mental component summary (MCS) — reported on a standardized scale with a mean of 50 and a standard deviation (SD) of 10, based on a US general population.

EQ-5D measures the current health status using five items (mobility, self-care, usual activities, pain/discomfort and anxiety/depression) with three response levels: no problems (level 1), some problems (level 2) and extreme problems (level 3) ${ }^{19}$. This instrument also contains the EQVAS, a 20-cm visual analogue scale that is scored from 0 (worst imaginable health) to 100 (best imaginable health). The scores obtained using this descriptive system were further converted into a utility score using population-derived weights ${ }^{20}$, where 0 represents being dead and 1 represents perfect health.

\section{Blood sampling and measures of biomarkers}

Peripheral venous blood was drawn into pyrogen-free tubes with EDTA as the anticoagulant. The tubes were immediately immersed in melting ice and centrifuged within $30 \mathrm{~min}$ at 
$2000 \times g$ for $20 \mathrm{~min}$ to obtain platelet-poor plasma. All samples were stored at $-80^{\circ} \mathrm{C}$ until being analysed. Routine blood samples were analysed by use of commercial methods.

Endothelial activation was assessed using the soluble vascular cell-adhesion molecule 1 (sVCAM-1), von Willebrand factor (vWF) and asymmetric dimethylarginine (ADMA). Creactive protein (CRP) and sVCAM-1 were analysed using enzyme immunoassays with validated antibody pairs (R\&D Systems, Stillwater, MN, USA), vWF was analysed using validated antibody pairs (DakoCytomation, Oslo, Norway) with a parallel diluted plasma pool as the standard, and ADMA were measured by high-performance liquid chromatography and precolumn derivatization with $o$-phthaldialdehyde (Sigma Chemicals, St. Louis, MO, USA), as described in detail elsewhere with minor modifications ${ }^{21}$. The intra- and interassay coefficients of variation for all measurements were $<10 \%$.

\section{Statistical analysis}

The normality of the variables was assessed by examining histograms. Data are presented as mean $\pm \mathrm{SD}$ or $n(\%)$ values, as appropriate. The independent-samples $t$-test or Fisher's exact test was used as appropriate to assess differences between groups.

The effects of the intervention on coronary physiology indices, health status and biomarkers of endothelial activation in the treatment group compared to the placebo group were assessed using multiple linear regression analyses. The 6-month values were used as the dependent variable according to randomization groups and controlled for preintervention values, and only subjects with paired observations were included in the analysis.

Statistical analyses were performed with IBM SPSS Statistics (version 24, IBM, Armonk, NY, USA). The threshold for statistical significance was set at $p<0.05$, and all tests were twosided. 


\section{RESULTS}

\section{Patient characteristics}

Among the 81 patients invited to participate, 66 patients were randomized into the rosuvastatin and placebo groups. The characteristics of the excluded patients did not differ significantly from those of the included patients (e.g., age, blood work, health status and echocardiographically assessed ejection fraction; data not shown), with the exception of the mean diastolic blood pressure being higher in the non-randomized group (81 $\mathrm{mmHg}$ vs 76 $\mathrm{mmHg}, p=0.01$ ). The characteristics of the final study population consisting of 33 patients in each group were well balanced with respect to age, medical history, medications and bloodwork assessments (Table 1). Overall, 10 patients were lost to follow-up (5 in each group): 2 did not take the study drug, 1 declined a second left-heart catheterization and 7 simply did not attend the scheduled follow-up. Apart from the total serum cholesterol level being lower in subjects lost to follow-up, there were no statistically significant differences in baseline characteristics between patients lost to follow-up and patients who completed follow-up (data not shown). The medications taken (angiotensin-converting enzyme inhibitors, angiotensin II receptor blockers, beta-blockers, calcium-channel blockers and aspirin) were comparable between the two study groups both at the baseline and follow-up investigations (Tables 1 and 2). There were no adverse events necessitating withdrawal of the study drugs. Tablet counts at the 6-month follow-up revealed a prescription adherence rate of $>80 \%$ among all patients who completed the 6-month follow-up.

\section{Coronary physiological assessments}

IMR was $14.6(\mathrm{SD} 5.7) \mathrm{mmHg} \cdot \mathrm{s}$ in the placebo group and $16.5(\mathrm{SD} 7.5) \mathrm{mmHg} \cdot \mathrm{s}$ in the rosuvastatin group $(p=0.24)$ at baseline (Table 3$)$. Similarly, there were no differences in other 
haemodynamic or coronary physiology measurements and indices at the baseline assessment, except for the mean resting heart rate being higher in the placebo group $(p=0.05)$ (Table 3$)$. Microvascular dysfunction defined as IMR $>20.8 \mathrm{mmHg} \cdot \mathrm{s}$ was observed in $11(17 \%)$ patients at baseline ( 3 and 8 in the placebo and rosuvastatin groups, respectively), with no difference at follow-up (4 and 6 patients, respectively). Similarly, CFR was $<2.5$ in six patients in each group, with no differences between the two groups at follow-up (four and three patients in the rosuvastatin and placebo groups, respectively). At the 6-month follow-up, IMR was 14.4 (SD 6.5) $\mathrm{mmHg} \cdot \mathrm{s}$ in the placebo group and $14.2(\mathrm{SD} 5.8) \mathrm{mmHg} \cdot \mathrm{s}$ in the rosuvastatin group. IMR, FFR, CFR and relevant haemodynamic measures did not differ significantly between the two study groups at follow-up controlled for preintervention values (Table 3).

\section{Health status}

The PCS and MCS scores for SF-36 and the EQVAS and EQ-5D scores at baseline and follow-up for both groups are listed in Table 4. Linear regression analysis of the effect of 6 months of rosuvastatin treatment compared to placebo and controlled for the preintervention assessments revealed no statistically significant differences in health-status scores (Table 4).

\section{Biochemical effects}

As expected, the cholesterol levels at the 6-month follow-up were significantly lower in the rosuvastatin group than in the placebo group (Table 3). Importantly, at 6-month follow-up, the CRP levels were also significantly lower in the rosuvastatin group than with placebo (Table 3). In contrast, natriuretic peptides, troponins and markers of endothelial activation (i.e., vWF, sVCAM-1 and ADMA) showed no differences between the placebo and rosuvastatin groups at the follow-up controlled for preintervention values (Table 3).

\section{DISCUSSION}


The key finding of this randomized, double-blinded study of 66 unselected women with chest pain but with no obstructive CAD was that 6 months of high-dose statin treatment did not significantly influence IMR values (Figure 2), health status or markers of endothelial activation. In contrast, the lipid profile was significantly improved, and the CRP levels significantly reduced in the rosuvastatin group. IMR values were comparable to values in a healthy reference population previously reported from our hospital ${ }^{17}$. In total $17 \%$ of the study population had IMR values indicating CMD.

To the best of our knowledge, this is the first double-blind, randomized study to explore the effect of statins on IMR values in women with chest pain and without obstructive CAD. Whereas rosuvastatin showed significant effects on lipid and CRP levels, it showed no effect on IMR, the occurrence of CMD defined as IMR $>20.8 \mathrm{mmHg} \cdot \mathrm{s}$ or markers of endothelial activation (Figure 3). The effects of statins on CMD have previously been studied in various settings but comparing the results of the present study with those of previous studies is difficult due to the small number of studies and the differences in end points and study designs. A study of the acute effect of atorvastatin showed a significant increase in the transthoracic Doppler-derived CFR in the atorvastatin group compared to no change in the placebo group ${ }^{8}$. The effect of statins on the Doppler-derived CFR was studied in 20 patients with angiographically slow coronary flow (20 mg of atorvastatin daily for 8 months) ${ }^{13}$ and in 56 hypertensive patients ( $10 \mathrm{mg}$ of rosuvastatin daily for $12 \mathrm{months})^{22}$, with both studies showing significant increases in CFR. However, these were not placebo-controlled studies, which may explain the divergent results compared to the current study.

A positive effect of statin treatment on endothelium-dependent vasodilatation as assessed by flow-mediated dilatation in the peripheral arteries has been demonstrated in studies of women with syndrome $\mathrm{X}^{23-25}$. However, it might not be valid to extrapolate these findings to the current study since adenosine primarily assesses endothelium-independent vasodilatation, and 
the effects on the peripheral vessels may differ from those on the cardiac vasculature. Previous studies of the effects of statins administered prior to percutaneous coronary interventions indicate that statin pretreatment is beneficial to the IMR ${ }^{26,27}$; however, the relevance of this finding to the current study is disputable, since epicardial CAD was an exclusion criterion.

Experimental studies have suggested that statins can exert endothelium-independent vasodilatation effects ${ }^{28,29}$, but clinical studies involving humans have been lacking. Our findings do not unambiguously support an endothelium-independent effect of rosuvastatin, since there was no statistically significant decrease in IMR after 6 months. Moreover, although rosuvastatin down-regulated the lipid and CRP levels, it did not affect markers of endothelial activation. However, reduction of CRP is prognostically important as shown among others in the Jupiter trial ${ }^{9,11}$. The short follow-up period in this study may explain lacking improvements in other outcome measures. Previous reviews have found conflicting effects of statins on ADMA, sVCAM-1 and vWF ${ }^{30-33}$. A possible explanation that needs to be investigated further is that such effects would require pre-existing hypercholesterolaemia, which was not present in the current study. Moreover, different statins might exert different effects. It is also possible that patients with residual inflammation could specifically benefit from such a therapy.

Both the SF-36 and EQ-5D scores in the present study were comparable to those found in previous studies of patients with stable angina or CAD ${ }^{34-37}$. The extent to which the sensitivity of generic health-status instruments is comparable to that of disease-specific questionnaires such as the Seattle Angina Questionnaire (SAQ) and Canadian Cardiovascular Society Angina Classification (CCS) has been questioned ${ }^{35}$. This correspondence may differ between patient populations and types of intervention. Furthermore, non-significant changes in SF-36 and EQ-5D scores are consistent with the lack of significant improvements in 
microvascular function as assessed with IMR. In contrast, a previous study found that combination therapy with atorvastatin and ramipril improved the health status of women with microvascular angina, as assessed with the SAQ ${ }^{25}$. We did not report the CCS class due to difficulties of classifying patients with atypical angina.

\section{Study limitations}

The current pilot study was designed to evaluate the effects of rosuvastatin on IMR, health status and markers of endothelial activation. The randomization was skewed in terms of the IMR distribution between the two randomization groups: the mean IMR was $1.9 \mathrm{mmHg} \cdot \mathrm{s}$ higher in the treatment group than in the placebo group at baseline, and the decrease of 2.3 $\mathrm{mmHg} \cdot \mathrm{s}$ in the former compared to $0.2 \mathrm{mmHg} \cdot \mathrm{s}$ in the latter did not reach statistical significance. The decrease may be attributed to a "regression to the mean" effect. In addition, the relatively small sample size of the study is a major limitation, which implies a risk of type II errors. Hence, the study power was insufficient for detecting a possible effect of rosuvastatin on IMR. In addition, the number of subjects lost to follow up, further weakens the statistical power. Based on the inclusion criteria, the study was not powered to see if women with CMD could represent a subgroup that will benefit from statin therapy. On the other hand, a major strength of the study is the repeated invasive assessment with paired analyses within subjects.

\section{CONCLUSIONS}

Rosuvastatin treatment for 6 months did not improve the health status, endothelial activation or microvascular function as assessed with the IMR method. However, caution is needed when interpreting these results due to skewness of the IMR at randomization and the smallness of the sample, leading to the possibility of type II errors. The study was not 
restricted to women with microvascular dysfunction (i.e., IMR $>20.8 \mathrm{mmHg}$ ), and

forthcoming studies should examine if these women could have an effect of statin

intervention.

\author{
Reference List
}

(1) Quyyumi AA. Women and ischemic heart disease: pathophysiologic implications from the Women's Ischemia Syndrome Evaluation (WISE) Study and future research steps. $J$ Am Coll Cardiol 2006;47:S66-S71.

(2) Jespersen L, Hvelplund A, Abildstrom SZ, Pedersen F, Galatius S, Madsen JK, Jorgensen E, Kelbaek $\mathrm{H}$, Prescott E. Stable angina pectoris with no obstructive coronary artery disease is associated with increased risks of major adverse cardiovascular events. Eur Heart J 2012;33:734-44.

(3) Johnson BD, Shaw LJ, Pepine CJ, Reis SE, Kelsey SF, Sopko G, Rogers WJ, Mankad S, Sharaf BL, Bittner V, Bairey Merz CN. Persistent chest pain predicts cardiovascular events in women without obstructive coronary artery disease: results from the NIH-NHLBI-sponsored Women's Ischaemia Syndrome Evaluation (WISE) study. Eur Heart J 2006;27:1408-15.

(4) Atienza F, Velasco JA, Brown S, Ridocci F, Kaski JC. Assessment of quality of life in patients with chest pain and normal coronary arteriogram (syndrome X) using a specific questionnaire. Clin Cardiol 1999;22:283-90.

(5) Olson MB, Kelsey SF, Matthews K, Shaw LJ, Sharaf BL, Pohost GM, Cornell CE, McGorray SP, Vido D, Bairey Merz CN. Symptoms, myocardial ischaemia and quality of life in women: results from the NHLBI-sponsored WISE Study. Eur Heart J 2003;24:1506-14.

(6) Pepine CJ, Ferdinand KC, Shaw LJ, Light-McGroary KA, Shah RU, Gulati M, Duvernoy C, Walsh MN, Bairey Merz CN. Emergence of Nonobstructive Coronary Artery Disease: A Woman's Problem and Need for Change in Definition on Angiography. J Am Coll Cardiol 2015;66:1918-33.

(7) Undas A, Brummel-Ziedins KE, Mann KG. Statins and blood coagulation. Arterioscler Thromb Vasc Biol 2005;25:287-94.

(8) Hinoi T, Matsuo S, Tadehara F, Tsujiyama S, Yamakido M. Acute effect of atorvastatin on coronary circulation measured by transthoracic Doppler echocardiography in patients without coronary artery disease by angiography. Am J Cardiol 2005;96:89-91.

(9) Ridker PM, Danielson E, Fonseca FA, Genest J, Gotto AM, Jr., Kastelein JJ, Koenig W, Libby P, Lorenzatti AJ, MacFadyen JG, Nordestgaard BG, Shepherd J, Willerson JT, Glynn RJ. Reduction in Creactive protein and LDL cholesterol and cardiovascular event rates after initiation of rosuvastatin: a prospective study of the JUPITER trial. Lancet 2009;373:1175-82.

(10) Maron DJ, Fazio S, Linton MF. Current perspectives on statins. Circulation 2000;101:207-13.

(11) Ridker PM, MacFadyen J, Libby P, Glynn RJ. Relation of baseline high-sensitivity C-reactive protein level to cardiovascular outcomes with rosuvastatin in the Justification for Use of statins in Prevention: an Intervention Trial Evaluating Rosuvastatin (JUPITER). Am J Cardiol 2010;106:204-9.

(12) Zhang X, Li Q, Zhao J, Li X, Sun X, Yang H, Wu Z, Yang J. Effects of combination of statin and calcium channel blocker in patients with cardiac syndrome X. Coron Artery Dis 2014;25:40-4. 
(13) Caliskan M, Erdogan D, Gullu H, Topcu S, Ciftci O, Yildirir A, Muderrisoglu H. Effects of atorvastatin on coronary flow reserve in patients with slow coronary flow. Clin Cardiol 2007;30:475-9.

(14) Palinski W. New evidence for beneficial effects of statins unrelated to lipid lowering. Arterioscler Thromb Vasc Biol 2001;21:3-5.

(15) Fearon WF, Balsam LB, Farouque HM, Caffarelli AD, Robbins RC, Fitzgerald PJ, Yock PG, Yeung AC. Novel index for invasively assessing the coronary microcirculation. Circulation 2003;107:3129-32.

(16) Lang RM, Badano LP, Mor-Avi V, Afilalo J, Armstrong A, Ernande L, Flachskampf FA, Foster E, Goldstein SA, Kuznetsova T, Lancellotti P, Muraru D, Picard MH, Rietzschel ER, Rudski L, Spencer KT, Tsang W, Voigt JU. Recommendations for cardiac chamber quantification by echocardiography in adults: an update from the American Society of Echocardiography and the European Association of Cardiovascular Imaging. J Am Soc Echocardiogr 2015;28:1-39.

(17) Solberg OG, Ragnarsson A, Kvarsnes A, Endresen K, Kongsgard E, Aakhus S, Gullestad L, Stavem K, Aaberge L. Reference interval for the index of coronary microvascular resistance. EuroIntervention 2014;9:1069-75.

(18) Ware JE, Jr., Sherbourne CD. The MOS 36-item short-form health survey (SF-36). I. Conceptual framework and item selection. Med Care 1992;30:473-83.

(19) EuroQol--a new facility for the measurement of health-related quality of life. Health Policy 1990;16:199-208.

(20) Dolan P. Modeling valuations for EuroQol health states. Med Care 1997;35:1095-108.

(21) Eid HM, Eritsland J, Larsen J, Arnesen H, Seljeflot I. Increased levels of asymmetric dimethylarginine in populations at risk for atherosclerotic disease. Effects of pravastatin. Atherosclerosis 2003;166:27984.

(22) Sun BJ, Hwang E, Jang JY, Kim DH, Song JM, Kang DH. Effect of rosuvastatin on coronary flow reserve in patients with systemic hypertension. Am J Cardiol 2014;114:1234-7.

(23) Kayikcioglu M, Payzin S, Yavuzgil O, Kultursay H, Can LH, Soydan I. Benefits of statin treatment in cardiac syndrome-X1. Eur Heart J 2003;24:1999-2005.

(24) Fabian E, Varga A, Picano E, Vajo Z, Ronaszeki A, Csanady M. Effect of simvastatin on endothelial function in cardiac syndrome X patients. Am J Cardiol 2004;94:652-5.

(25) Pizzi C, Manfrini O, Fontana F, Bugiardini R. Angiotensin-converting enzyme inhibitors and 3hydroxy-3-methylglutaryl coenzyme A reductase in cardiac Syndrome X: role of superoxide dismutase activity. Circulation 2004;109:53-8.

(26) Fujii K, Kawasaki D, Oka K, Akahori H, Iwasaku T, Fukunaga M, Eguchi A, Sawada H, Masutani M, Lee-Kawabata M, Tsujino T, Ohyanagi M, Masuyama T. The impact of pravastatin pre-treatment on periprocedural microcirculatory damage in patients undergoing percutaneous coronary intervention. JACC Cardiovasc Interv 2011;4:513-20.

(27) Lee BK, Koo BK, Nam CW, Doh JH, Chung WY, Cho BR, Fearon WF. Does Pre-Treatment with High Dose Atorvastatin Prevent Microvascular Dysfunction after Percutaneous Coronary Intervention in Patients with Acute Coronary Syndrome? Korean Circ J 2016;46:472-80.

(28) Lorkowska B, Chlopicki S. Statins as coronary vasodilators in isolated bovine coronary arteries-involvement of PGI2 and NO. Prostaglandins Leukot Essent Fatty Acids 2005;72:133-8.

(29) McGowan CL, Murai H, Millar PJ, Notarius CF, Morris BL, Floras JS. Simvastatin reduces sympathetic outflow and augments endothelium-independent dilation in non-hyperlipidaemic primary hypertension. Heart 2013;99:240-6. 
(30) Sibal L, Agarwal SC, Home PD, Boger RH. The Role of Asymmetric Dimethylarginine (ADMA) in Endothelial Dysfunction and Cardiovascular Disease. Curr Cardiol Rev 2010;6:82-90.

(31) Greenwood J, Mason JC. Statins and the vascular endothelial inflammatory response. Trends Immunol 2007;28:88-98.

(32) Davignon J. Beneficial cardiovascular pleiotropic effects of statins. Circulation 2004;109:III39-III43.

(33) Sahebkar A, Serban C, Ursoniu S, Mikhailidis DP, Undas A, Lip GY, Bittner V, Ray K, Watts GF, Hovingh GK, Rysz J, Kastelein JJ, Banach M. The impact of statin therapy on plasma levels of von Willebrand factor antigen. Systematic review and meta-analysis of randomised placebo-controlled trials. Thromb Haemost 2016;115:520-32.

(34) Wijeysundera HC, Farshchi-Zarabi S, Witteman W, Bennell MC. Conversion of the Seattle Angina Questionnaire into EQ-5D utilities for ischemic heart disease: a systematic review and catalog of the literature. Clinicoecon Outcomes Res 2014;6:253-68.

(35) Dougherty CM, Dewhurst T, Nichol WP, Spertus J. Comparison of three quality of life instruments in stable angina pectoris: Seattle Angina Questionnaire, Short Form Health Survey (SF-36), and Quality of Life Index-Cardiac Version III. J Clin Epidemiol 1998;51:569-75.

(36) Spertus JA, Winder JA, Dewhurst TA, Deyo RA, Fihn SD. Monitoring the quality of life in patients with coronary artery disease. Am J Cardiol 1994;74:1240-4.

(37) Wu J, Han Y, Xu J, Lu Y, Cong H, Zheng J, Sun H. Chronic stable angina is associated with lower health-related quality of life: evidence from Chinese patients. PLoS One 2014;9:e97294.

Figure legends

Figure 1.

Patient flow chart. CAD, coronary artery disease; FU, follow-up.

Figure 2.

Effect of rosuvastatin on IMR at baseline and 6-month follow-up compared to placebo, mean values \pm SD. $p=0.55$ for IMR at 6 -month follow-up in the rosuvastatin group compared to the placebo group controlled for preintervention values (multiple linear regression).

Figure 3. 
In addition to improvement of lipid profile, statins exhibit anti-inflammatory effects known to inhibit progression and development of epicardial coronary artery disease. Despite significant decrease of total cholesterol, LDL-cholesterol and CRP; coronary microvascular function as assessed with IMR was not significantly improved. 
Table 1. Baseline characteristics of the included patients. Data are mean $\pm \mathrm{SD}$ or $n(\%)$ values.

\begin{tabular}{|c|c|c|}
\hline & Placebo $(n=33)$ & Rosuvastatin $(n=33)$ \\
\hline Age, years & $52.7 \pm 9.2$ & $55.5 \pm 9.2$ \\
\hline Body mass index, $\mathrm{kg} / \mathrm{m}^{2}$ & $26.5 \pm 4.8$ & $25.8 \pm 4.1$ \\
\hline Hypertension & $7(21)$ & $8(24)$ \\
\hline Diabetes mellitus & $1(3)$ & $1(3)$ \\
\hline Current or former smoker & $24(73)$ & $20(61)$ \\
\hline Family history of CAD & $27(82)$ & $26(79)$ \\
\hline Dyslipidaemia $(n=33 / 32)^{*}$ & $4(12)$ & $4(12)$ \\
\hline Typical angina & $16(49)$ & $18(55)$ \\
\hline Atypical angina & $17(51)$ & $15(45)$ \\
\hline \multicolumn{3}{|l|}{ Relevant cardiac medication } \\
\hline ACEi/ARB & $4(12)$ & $4(12)$ \\
\hline Beta blocker & $12(36)$ & $8(24)$ \\
\hline Calcium-channel blocker & $4(12)$ & $2(6)$ \\
\hline
\end{tabular}


Aspirin

$25(76)$

$19(58)$

Biochemistry

Total cholesterol, $\mathrm{mmol} / \mathrm{L}$

$\begin{array}{cc}5.7 \pm 1.3 & 5.8 \pm 1.0 \\ 3.7 \pm 1.2 & 3.7 \pm 0.8 \\ 1.6 \pm 0.5 & 1.7 \pm 0.5 \\ 1.6 \pm 0.8 & 1.4 \pm 0.6 \\ 13.8 \pm 0.9 & 14.0 \pm 0.8 \\ 65 \pm 11 & 64 \pm 7 \\ 274 \pm 62 & 266 \pm 57 \\ 5.6 \pm 0.4 & 5.6 \pm 0.5 \\ 7.8 \pm 5.6 & 13.1 \pm 12.8 \\ 7.6 \pm 2.5 & 7.5 \pm 2.4 \\ 2.1 \pm 2.5 & 1.2 \pm 1.1 \\ 370 \pm 244 & 379 \pm 195 \\ 0.55 \pm 0.09 & 0.54 \pm 0.09\end{array}$

LDL, $\mathrm{mmol} / \mathrm{L}$

HDL, mmol/L

Triglycerides, $\mathrm{mmol} / \mathrm{L}$

Haemoglobin, g/dL

Creatinine, $\mu \mathrm{mol} / \mathrm{L}$

Uric acid, $\mu \mathrm{mol} / \mathrm{L}(n=22 / 21) *$

HbA1c, \%

NT-pro-BNP, pmol/L $(n=30 / 27)^{*}$

Troponin T, ng/L

CRP, mg/L

vWF, arbitrary units $(n=32 / 32) *$

$0.55 \pm 0.09$

$0.54 \pm 0.09$ 
sVCAM-1, $\mu \mathrm{g} / \mathrm{mL}(n=32 / 32)^{*}$

\section{Echocardiography}

Interventricular septum diameter, $\mathrm{cm}(n=33 / 32)$ *

Left ventricular end-diastolic diameter, $\mathrm{cm}(n=33 / 32)^{*}$

Left ventricular posterior wall diameter, $\mathrm{cm}(n=32 / 32)^{*}$

Left atrium area, $\mathrm{cm}^{2}(n=33 / 32)^{*}$

Right atrium area, $\mathrm{cm}^{2}(n=32 / 29) *$

E/e', ratio $(n=32 / 30)^{*}$

Cardiac index, $\mathrm{L} / \mathrm{min} / \mathrm{m}^{2}(n=30 / 31)^{*}$

Ejection fraction, $\%(n=32 / 33) *$
$1.2 \pm 1.2$

$0.8 \pm 0.2$

$4.8 \pm 0.4$

$0.7 \pm 0.1$

$18.9 \pm 4.2$

$16.5 \pm 3.1$

$8.5 \pm 2.2$

$2.8 \pm 0.4$

$60.5 \pm 6.6$
$1.3 \pm 0.5$

$0.8 \pm 0.1$

$4.7 \pm 0.5$

$0.7 \pm 0.1$

$19.3 \pm 3.0$

$16.2 \pm 2.8$

$8.1 \pm 2.8$

$2.6 \pm 0.5$

$61.3 \pm 6.0$

${ }^{*} n=$ denotes numbers in placebo/rosuvastatin groups, respectively.

$\mathrm{CAD}$, coronary artery disease; ACEi, angiotensin-converting enzyme inhibitor; ARB, angiotensin II receptor blocker; LDL, low-density lipoprotein; HDL, high-density lipoprotein; HbAlc, glycated haemoglobin; NT-pro-BNP, N-terminal-pro-brain-natriuretic peptide; CRP, Creactive protein; ADMA, asymmetric dimethylarginine; sVCAM-1, soluble vascular-cell adhesion molecule 1; E, peak velocity of early transmitral Doppler flow; e', early diastolic tissue Doppler mitral annular velocity. 
Table 2. Cardiac medication and biochemistry at follow-up. Data are mean \pm SD or $n(\%)$ values.

\begin{tabular}{|c|c|c|c|}
\hline & Placebo $(n=29)$ & Rosuvastatin $(n=28)$ & $p^{* *}$ \\
\hline \multicolumn{4}{|l|}{ Relevant cardiac medication } \\
\hline ACEi/ARB & $3(10)$ & $6(21)$ & 0.30 \\
\hline Beta blocker & $7(24)$ & $8(29)$ & 0.78 \\
\hline Calcium-channel blocker & $2(7)$ & $2(7)$ & 1.0 \\
\hline Aspirin & $17(59)$ & $11(39)$ & 0.19 \\
\hline \multicolumn{4}{|l|}{ Biochemistry } \\
\hline Total cholesterol, mmol/L & $5.6 \pm 1.3$ & $3.9 \pm 0.8$ & $<0.001$ \\
\hline $\mathrm{LDL}, \mathrm{mmol} / \mathrm{L}$ & $3.6 \pm 1.2$ & $1.8 \pm 0.7$ & $<0.001$ \\
\hline $\mathrm{HDL}, \mathrm{mmol} / \mathrm{L}$ & $1.5 \pm 0.5$ & $1.9 \pm 0.5$ & 0.03 \\
\hline Triglycerides, $\mathrm{mmol} / \mathrm{L}(n=23,25) *$ & $1.6 \pm 0.7$ & $0.9 \pm 0.4$ & $<0.001$ \\
\hline Haemoglobin, g/dL & $13.9 \pm 0.7$ & $13.9 \pm 1.0$ & 0.77 \\
\hline Creatinine, $\mu \mathrm{mol} / \mathrm{L}$ & $67 \pm 10$ & $66 \pm 10$ & 0.49 \\
\hline Uric acid, $\mu \mathrm{mol} / \mathrm{L}(n=19,13) *$ & $305 \pm 107$ & $267 \pm 54$ & 0.24 \\
\hline
\end{tabular}


HbA1c, $\%(n=27,27)$

NT-pro-BNP, pmol/L $(n=18 / 18)$ *

Troponin T, ng/L $(n=29 / 27)$ *

CRP, mg/L $(n=28 / 27)$ *

vWF, arbitrary units $(n=27 / 24) *$

ADMA, $\mu \mathrm{mol} / \mathrm{L}(n=26 / 26)^{*}$

sVCAM, $\mu \mathrm{g} / \mathrm{mL}(n=27 / 24)^{*}$
$5.5 \pm 0.4$

$7.4 \pm 5.9$

$6.7 \pm 2.2$

$2.6 \pm 3.0$

$389 \pm 245$

$0.54 \pm 0.08$

$1.3 \pm 0.6$
$5.6 \pm 0.6$

$11.8 \pm 8.0$

$6.9 \pm 2.3$

$0.6 \pm 0.5$

$373 \pm 232$

$0.53 \pm 0.10$

$1.2 \pm 0.5$
0.53

0.07

0.75

0.002

$0.62^{* * *}$

$0.73^{* * *}$

$0.22 * * *$

$*_{n}=$ denotes numbers in placebo/rosuvastatin groups.

** Independent-samples $t$-test or Fisher's exact test as appropriate.

*** $p$ values for comparisons between rosuvastatin and placebo groups after 6-month follow-up controlled for preintervention values (multiple linear regression analysis). 
Table 3. Haemodynamic and coronary physiology measures at baseline and follow-up. Data are mean $\pm \mathrm{SD}$ values.

\begin{tabular}{|c|c|c|c|c|c|}
\hline & \multicolumn{2}{|c|}{ Placebo } & \multicolumn{2}{|c|}{ Rosuvastatin } & \multirow[b]{2}{*}{$p^{*}$} \\
\hline & Baseline $(n=33)$ & Follow-up $(n=28)$ & Baseline $(n=33)$ & Follow-up $(n=28)$ & \\
\hline Aortic systolic pressure, $\mathrm{mmHg}$ & $117 \pm 17$ & $111 \pm 12$ & $116 \pm 17$ & $113 \pm 17$ & 0.78 \\
\hline Aortic diastolic pressure, $\mathrm{mmHg}$ & $66 \pm 10$ & $67 \pm 7$ & $64 \pm 6$ & $63 \pm 7$ & 0.14 \\
\hline Heart rate at baseline, beats/min & $75 \pm 9 * *$ & $73 \pm 9$ & $70 \pm 11^{* *}$ & $68 \pm 11$ & 0.25 \\
\hline Heart rate at maximum hyperaemia, & $91 \pm 14$ & $90 \pm 15$ & $87 \pm 12$ & $84 \pm 12$ & 0.28 \\
\hline beats $/ \min$ & & & & & \\
\hline$P_{\mathrm{a}}$ at maximum hyperaemia, $\mathrm{mmHg}$ & $78 \pm 12$ & $77 \pm 11$ & $78 \pm 11$ & $75 \pm 9$ & 0.36 \\
\hline$P_{\mathrm{d}}$ at maximum hyperaemia, $\mathrm{mmHg}$ & $71 \pm 13$ & $71 \pm 12$ & $71 \pm 10$ & $70 \pm 8$ & 0.40 \\
\hline$T_{\mathrm{mnr}}, \mathrm{s}$ & $0.81 \pm 0.29$ & $0.93 \pm 0.46$ & $0.95 \pm 0.41$ & $0.96 \pm 0.41$ & 0.30 \\
\hline$T_{\mathrm{mnh}}, \mathrm{s}$ & $0.21 \pm 0.09$ & $0.20 \pm 0.08$ & $0.23 \pm 0.10$ & $0.21 \pm 0.10$ & 0.84 \\
\hline FFR & $0.91 \pm 0.05$ & $0.92 \pm 0.04$ & $0.92 \pm 0.04$ & $0.93 \pm 0.04$ & 0.68 \\
\hline CFR & $4.3 \pm 2.0$ & $5.3 \pm 3.2$ & $4.6 \pm 2.2$ & $5.2 \pm 2.7$ & 0.89 \\
\hline $\mathrm{IMR}, \mathrm{mmHg} \cdot \mathrm{s}$ & $14.6 \pm 5.7$ & $14.4 \pm 6.5$ & $16.5 \pm 7.5$ & $14.2 \pm 5.8$ & 0.55 \\
\hline
\end{tabular}


* $p$ values for comparisons between rosuvastatin and placebo groups after 6-month follow-up controlled for preintervention values (multiple linear regression analysis).

** $p=0.05$ for difference in heart rate at baseline between the two study groups.

$P_{\mathrm{a}}$, aortic pressure; $P_{\mathrm{d}}$, distal coronary artery pressure; $T_{\mathrm{mnr}}$, resting transit time; $T_{\mathrm{mnh}}$, hyperaemic transit time ; FFR, fractional flow reserve; CFR, coronary flow reserve; IMR, index of microvascular resistance. 
Table 4. Health-related quality-of-life scores of included patients at baseline and follow-up. Data are mean $\pm \mathrm{SD}$ values.

\begin{tabular}{|c|c|c|c|c|c|}
\hline & \multicolumn{2}{|c|}{ Placebo } & \multicolumn{2}{|c|}{ Rosuvastatin } & \multirow[b]{2}{*}{$p^{*}$} \\
\hline & Baseline $(n=31)$ & Follow-up $(n=28)$ & Baseline $(n=32)$ & Follow-up $(n=29)$ & \\
\hline$S F-36$ & & & & & \\
\hline Physical functioning & $73.9 \pm 20.7$ & $78.8 \pm 17.8$ & $74.7 \pm 17.6$ & $86.0 \pm 14.5$ & 0.15 \\
\hline Physical role limitations & $38.7 \pm 37.6$ & $55.4 \pm 45.8$ & $48.4 \pm 40.1$ & $69.8 \pm 38.0$ & 0.43 \\
\hline Bodily pain & $52.7 \pm 16.0$ & $55.5 \pm 23.7$ & $54.8 \pm 25.2$ & $60.1 \pm 25.0$ & 0.67 \\
\hline General perceived health & $60.4 \pm 18.3$ & $66.3 \pm 21.8$ & $62.2 \pm 22.0$ & $72.1 \pm 23.2$ & 0.26 \\
\hline Vitality & $36.6 \pm 22.4$ & $44.6 \pm 23.6$ & $42.4 \pm 23.6$ & $54.8 \pm 22.1$ & 0.42 \\
\hline Social functioning & $71.4 \pm 28.0$ & $76.3 \pm 25.5$ & $75.8 \pm 23.8$ & $78.5 \pm 23.6$ & 0.97 \\
\hline Emotional role limitations & $74.2 \pm 41.0$ & $82.1 \pm 33.3$ & $67.7 \pm 41.0$ & $79.8 \pm 36.7(n=28)$ & 0.65 \\
\hline Mental health & $76.5 \pm 11.6$ & $79.3 \pm 14.1$ & $73.5 \pm 15.4$ & $78.4 \pm 15.3$ & 0.57 \\
\hline Physical component summary** & $39.0 \pm 9.3$ & $42.4 \pm 10.6(n=27)$ & $41.5 \pm 10.5$ & $47.1 \pm 10.4(n=28)$ & 0.67 \\
\hline Mental component summary** & $48.9 \pm 8.8$ & $50.9 \pm 8.7(n=27)$ & $47.9 \pm 11.3$ & $50.3 \pm 10.0(n=28)$ & 0.52 \\
\hline
\end{tabular}




\section{$E Q-5 D$}

\section{EQVAS}

$61 \pm 20(n=30)$

$70 \pm 18(n=29)$

$67 \pm 18(n=29)$

$75 \pm 21$

0.88

EQ-5D index

$0.66 \pm 0.22(n=30)$

$0.81 \pm 0.13(n=29)$

$0.72 \pm 0.23$

$0.78 \pm 0.22$

0.21

SF-36, 36-item Short Form Health Survey; EQ-5D, 5-dimension EuroQol; EQVAS, EQ-5D visual analogue scale.

* $p$ values for comparisons between rosuvastatin and placebo groups after 6-month follow-up controlled for preintervention values (multiple linear regression analysis).

**Standardized for comparison with a US general population (mean of 50 and an SD of 10). 


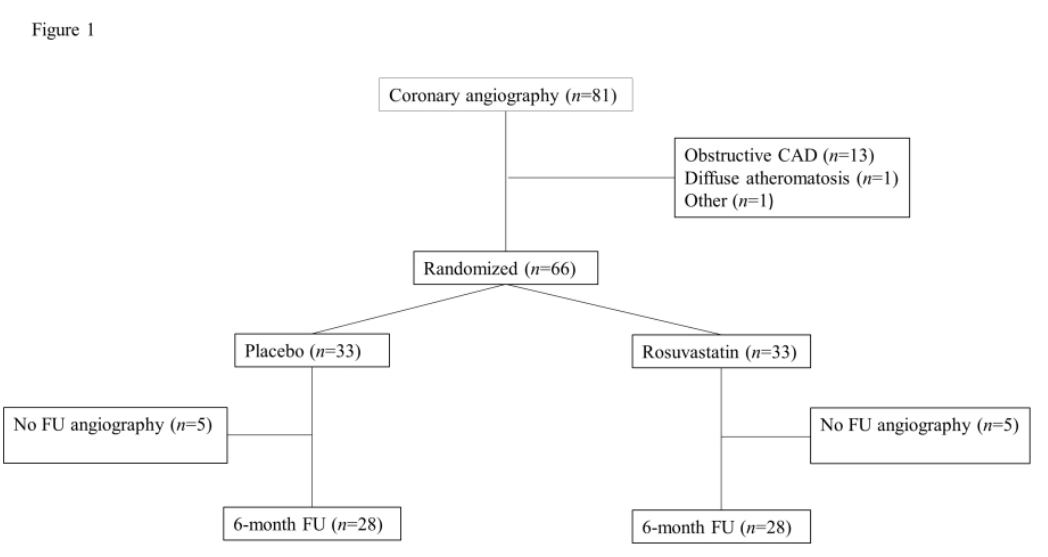

Patient flow chart. CAD, coronary artery disease; FU, follow-up. $338 \times 190 \mathrm{~mm}$ (300 x 300 DPI) 
Figure 2

Effect of rosuvastatin on IMR at baseline and 6-month follow-up compared to placebo, mean values \pm SD. $p=0.55$ for IMR at 6 -month follow-up in the rosuvastatin group compared to the placebo group controlled for preintervention values (multiple linear regression).

\section{$338 \times 190 \mathrm{~mm}(300 \times 300 \mathrm{DPI})$}


In addition to improvement of lipid profile, statins exhibit anti-inflammatory effects known to inhibit progression and development of epicardial coronary artery disease. Despite significant decrease of total cholesterol, LDL-cholesterol and CRP; coronary microvascular function as assessed with IMR was not significantly improved.

$338 \times 190 \mathrm{~mm}(300 \times 300 \mathrm{DPI})$ 


\title{
INDEX OF MICROVASCULAR RESISTANCE TO ASSESS THE EFFECT OF ROSUVASTATIN ON MICROVASCULAR FUNCTION IN WOMEN WITH CHEST PAIN AND NO OBSTRUCTIVE CORONARY ARTERY DISEASE. A DOUBLE-BLIND RANDOMIZED STUDY
}

\begin{abstract}
Ole Geir Solberg MD PhD ${ }^{1}$, Knut Stavem MD PhD MPH²,3, Asgrimur Ragnarsson MD ${ }^{5}$, Jan-Otto Beitnes MD PhD ${ }^{1}$, Rita Skårdal RN MSc${ }^{1}$, Ingebjørg Seljeflot $\mathrm{PhD}^{2,6}$, Thor Ueland $\mathrm{PhD}^{2,7,8}$, Pål Aukrust MD PhD $2,8,9$, Lars Gullestad MD PhD ${ }^{1,2,10}$, Lars Aaberge MD PhD ${ }^{1}$.
\end{abstract}

${ }^{1}$ Department of Cardiology, Oslo University Hospital, Rikshospitalet, Oslo, Norway.

${ }^{2}$ Institute of Clinical Medicine, University of Oslo, Faculty of Medicine, Oslo, Norway.

${ }^{3}$ Department of Pulmonary Medicine, Akershus University Hospital, Lørenskog, Norway.

${ }^{4}$ Department of Health Services Research, Akershus University Hospital, Lørenskog, Norway.

${ }^{5}$ Department of Radiology, Oslo University Hospital, Rikshospitalet, Oslo, Norway.

${ }^{6}$ Center for Clinical Heart Research, Department of Cardiology, Oslo University Hospital, Ullevål, Oslo, Norway.

${ }^{7}$ K.G. Jebsen TREC, University of Tromsø, Tromsø, Norway.

${ }^{8}$ Research Institute of Internal Medicine, Oslo University Hospital, Rikshospitalet, Oslo, Norway.

${ }^{9}$ Section of Clinical Immunology and Infectious Diseases, Oslo University Hospital, Rikshospitalet, Oslo, Norway.

${ }^{10}$ K.G. Jebsen Cardiac Research Centre and Centre for Heart Failure Research, Faculty of Medicine, Oslo University Hospital, Oslo, Norway.

Corresponding author: Ole Geir Solberg, Oslo University Hospital, Rikshospitalet, Department of Cardiology, POB 4950 Nydalen, 0424 Oslo, Norway.

E-mail: geosolb@online.no; ogsolber@ous-hf.no

Phone: $\quad+47-23070000$

Fax: $\quad+47-23071950$

Keywords: microvascular angina; index of microvascular resistance; statin; rosuvastatin; health-related quality of life; health status. 
Word count: 4360

The study was performed at Oslo University Hospital, Rikshospitalet, Department of Cardiology, POB 4950 Nydalen, 0424 Oslo, Norway.

Running head: Effect of rosuvastatin assessed with IMR 


\begin{abstract}
Introduction: Many women undergoing coronary angiography for chest pain have no or only minimal coronary artery disease (CAD). However, despite the lack of obstructive CAD, they still have an increased risk of major adverse cardiovascular events. Pleiotropic effects of statins may influence microvascular function, but if statins improve microvascular function in unselected chest pain patients is not well studied. This study assessed microvascular function by using the thermodilution-derived test "the index of microvascular resistance" (IMR) with the aim of determining the (i) IMR level in women with chest pain and non-obstructive CAD and if (ii) IMR is modified by high-dose statin treatment in these patients. Additional objectives were to identify the influence of statins on the health status as assessed with generic health questionnaires and on biomarkers of endothelial activation.
\end{abstract}

Materials and Methods: The study was a randomized, double-blind, single-centre trial comparing 6 months of rosuvastatin treatment with placebo. In total, 66 women without obstructive CAD were included. Mean age was 52.7 years and 55.5 years in the placebo and rosuvastatin group, respectively. Microvascular function was assessed using the IMR, health status was assessed using the SF-36 and EQ-5D questionnaires, and biochemical values were assessed at baseline and 6 months later.

Results and Conclusions: In the placebo group IMR was 14.6 (SD 5.7) at baseline and 14.4 (SD 6.5) at follow-up. In the rosuvastatin group IMR was 16.5 (SD 7.5) at baseline and 14.2 (SD 5.8) at follow-up. IMR did not differ significantly between the two study groups at follow-up controlled for preintervention values. C-reactive protein (CRP) was comparable between the groups at baseline, while at follow-up CRP was significantly lower in the rosuvastatin group compared to placebo $[0.6( \pm 0.5) \mathrm{mg} / \mathrm{L}$ vs $2.6( \pm 3.0) \mathrm{mg} / \mathrm{L} ; \mathrm{p}=0.002]$. Whereas rosuvastatin treatment for 6 months attenuated CRP levels, it did not improve 
microvascular function as assessed by IMR. (Clinical Trials.gov NCT 01582165. EUDRACT (2011-002630-39.3tcAZ) 


\section{INTRODUCTION}

Many women undergoing coronary angiography for chest pain have no or only minimal coronary artery disease (CAD) ${ }^{1,2}$. However, despite the lack of obstructive CAD, they still have an increased risk of major adverse cardiovascular events such as cardiovascular mortality, hospitalization for myocardial infarction, heart failure and stroke ${ }^{2}$. Furthermore, persistent chest pain predicts cardiovascular adverse events ${ }^{3}$ and is associated with impaired health status ${ }^{4,5}$. The ischaemic symptoms in non-obstructive CAD have diverse aetiologies ${ }^{6}$. In addition to their cholesterol-lowering effect, statins influence microvascular function and endothelial activation (which constitute part of their pleiotropic effects) ${ }^{7-13}$, at least partly involving increased bioavailability of nitric oxide, decreased levels of endothelin-1 and reduced oxidative stress ${ }^{14}$. However, the statin effect on microvascular function in general in patients with chest pain and no obstructive coronary artery disease, is not well studied. The extent to which statins also exert endothelium-independent effects that may improve ischaemic symptoms in non-obstructive CAD remains unclear. Because the coronary microcirculation cannot be directly visualized, it needs to be assessed using indirect methods. One such method, available during a routine diagnostic coronary angiography, is the thermodilution-derived functional test, the index of microvascular resistance (IMR) ${ }^{15}$, which primarily explores endothelium-independent coronary microvascular dysfunction (CMD) via the intravenous infusion of adenosine.

The objectives of the present study were to determine the (i) IMR level in women with chest pain and non-obstructive CAD and if (ii) IMR is modified by high-dose statin treatment in these patients. Additional objectives were to identify how statins influence the health status as assessed with generic health questionnaires and biomarkers of endothelial activation. The study therefore aimed to study a broad spectrum of patients with chest pain without 
significant $\mathrm{CAD}$ and was not limited to those with microvascular dysfunction testing the hypothesis that statins generally improve microvascular function, and that any improvement in microvascular function would improve the end-point included in the study.

\section{MATERIALS AND METHODS}

\section{Study design}

This study was a randomized, double-blind, single-centre trial comparing 6 months of rosuvastatin treatment with placebo. Eligible women who had been referred to receive coronary angiography from 2012 to 2016 were recruited for inclusion in the study. The study protocol was approved by the South East Department of the Norwegian Regional Committee for Medical and Health Research Ethics (Approval code 2011/1600) and the local review board of the hospital. The study was conducted in compliance with Good Clinical Practice and with the tenets of the Declaration of Helsinki and was registered at ClinicalTrials.gov (NCT 01582165) and EUDRACT (2011-002630-39.3tcAZ).

\section{Study design and participants}

Oslo University Hospital, Rikshospitalet is a tertiary referral centre in Oslo, Norway for interventional cardiology. Female patients aged 30-70 years with suspected ischaemic chest pain and unknown coronary anatomy who were referred for coronary angiography as part of a diagnostic workup were eligible for inclusion in this study. In total, 81 women were screened. Coronary angiography revealed that 13 had obstructive CAD [defined as a fractional flow reserve (FFR) of $\leq 0.80$ or at least 1 occluded major coronary artery], 1 had diffuse atheromatosis and other reasons for statin therapy, and 1 was unable to comply with the study 
protocol due to panic disorder (Figure 1). Hence, 66 women with angina pectoris and normal or near-normal coronary angiograms with FFR exceeding the ischaemic threshold of 0.80 were included in the study (Figure 1). Positive or equivocal findings in bicycle ergometry were a prerequisite for inclusion. Exclusion criteria were coronary artery stenosis $\geq 33 \%$ in any epicardial vessel, pregnancy or nursing, childbearing potential and not using contraception, short life expectancy, uncontrolled endocrine disease, uncontrolled arterial hypertension, structural heart disease, significant mental disorder including dementia or inability to comply with the protocol.

After diagnostic left-heart catheterization including a coronary physiology assessment, the patients were randomly assigned to 6 months of treatment with rosuvastatin or placebo in a double-blinded fashion. Written informed consent was obtained from all patients prior to performing heart catheterization.

\section{Randomization and study drugs}

The randomization scheme (in a 1:1 ratio for treatment:placebo) was generated by the Centre for Biostatistics and Epidemiology at the hospital using a computerized procedure. Numbered boxes with the placebo or the treatment drug (according to the randomization scheme) were consecutively dispatched to the included patients. The helpers who prepared the boxes were not otherwise involved in the study. Identical placebo and treatment-drug tablets were supplied free-of-charge by Astra Zeneca UK. The daily starting dose was $20 \mathrm{mg}$ of rosuvastatin or the matching placebo. The same dose was given throughout the study.

\section{Echocardiography}

Transthoracic images were obtained from parasternal and apical positions recording standard parasternal imaging planes using high-end echocardiography scanners (Vivid 7 $^{\mathrm{TM}}$ or E9 ${ }^{\mathrm{TM}}$, GE Vingmed, Horten, Norway) according to current recommendations ${ }^{16}$. Conventional 
greyscale cineloops as well as tissue Doppler loops and blood flow velocities as measured using Doppler flowmetry were recorded. Data for at least three consecutive representative heart beats were obtained and stored on a server.

\section{Heart catheterization and coronary physiological assessments}

Left-heart catheterization was performed mostly using a transradial approach with a 6-French arterial sheath and 6-French diagnostic and guiding catheters, and only in exceptional circumstances via the femoral artery. At the start of the procedure, 5,000 $\mathrm{U}$ of heparin, $2.5 \mathrm{mg}$ of verapamil and $200 \mu \mathrm{g}$ of glyceryl trinitrate were administered intra-arterially. Coronary physiological measurements were made with a pressure- and thermistor-equipped guide wire (PressureWire Certus, St. Jude Medical, St. Paul, MN, USA), with $200 \mu \mathrm{g}$ of glyceryl trinitrate administered via an intracoronary injection before making the measurements. Hyperaemia was obtained by the intravenous infusion of $140 \mu \mathrm{g} / \mathrm{kg} / \mathrm{min}$ adenosine. The procedure has been reported previously in detail ${ }^{17}$. In short, the aortic pressure $\left(P_{\mathrm{a}}\right)$ and distal coronary artery pressure $\left(P_{\mathrm{d}}\right)$ were measured in the presence and absence of hyperaemia. Both at baseline and during hyperaemia, 3-4 $\mathrm{mL}$ of room-temperature saline was injected into the investigated coronary artery, and the resting transit time $\left(T_{\mathrm{mnr}}\right)$ and hyperaemic transit time $\left(T_{\mathrm{mnh}}\right)$ were recorded. The coronary physiological indices were calculated as follows:

$\mathrm{FFR}=P_{\mathrm{d}} / P_{\mathrm{a}}(\leq 0.80$ indicates myocardial ischaemia due to epicardial CAD $)$.

$\mathrm{IMR}=P_{\mathrm{d}} \times T_{\mathrm{mnh}}$ [no definite threshold has been established, but $>20.8 \mathrm{mmHg} \cdot \mathrm{s}$ was used to detect CMD based on a previous study in our hospital ${ }^{17}$ ].

$\mathrm{CFR}=T_{\mathrm{mnr}} / T_{\mathrm{mnh}}$ (coronary flow reserve, where $<2.5$ or $<2.0$ is considered pathological).

FFR was averaged over three heart beats for which its value was the lowest. 
The continuous equalization of pressures was confirmed at the end of the procedure by repositioning the pressure wire in the ostium of the vessel. Care was taken to ensure that the coronary physiological measurements were made in approximately the same position in the vessel during the second heart catheterization procedure.

\section{Health status}

Health status was assessed using version 1.2 of the generic 36-item Short Form Health Survey (SF-36) and the 5-dimension EuroQol (EQ-5D) questionnaires at baseline and 6 months later. SF-36 assesses the following eight dimensions of health during the previous 4 weeks: Physical functioning, physical role limitations, bodily pain, general perceived health, vitality, social functioning, emotional role limitations and mental health ${ }^{18}$. The SF-36 score ranges from 0 to 100, with higher scores indicating better health. The dimension scores were aggregated to provide two summary scales - the physical component summary (PCS) and mental component summary (MCS) — reported on a standardized scale with a mean of 50 and a standard deviation (SD) of 10, based on a US general population.

EQ-5D measures the current health status using five items (mobility, self-care, usual activities, pain/discomfort and anxiety/depression) with three response levels: no problems (level 1), some problems (level 2) and extreme problems (level 3) ${ }^{19}$. This instrument also contains the EQVAS, a 20-cm visual analogue scale that is scored from 0 (worst imaginable health) to 100 (best imaginable health). The scores obtained using this descriptive system were further converted into a utility score using population-derived weights ${ }^{20}$, where 0 represents being dead and 1 represents perfect health.

\section{Blood sampling and measures of biomarkers}

Peripheral venous blood was drawn into pyrogen-free tubes with EDTA as the anticoagulant. The tubes were immediately immersed in melting ice and centrifuged within $30 \mathrm{~min}$ at 
$2000 \times g$ for 20 min to obtain platelet-poor plasma. All samples were stored at $-80^{\circ} \mathrm{C}$ until being analysed. Routine blood samples were analysed by use of commercial methods.

Endothelial activation was assessed using the soluble vascular cell-adhesion molecule 1 (sVCAM-1), von Willebrand factor (vWF) and asymmetric dimethylarginine (ADMA). Creactive protein (CRP) and sVCAM-1 were analysed using enzyme immunoassays with validated antibody pairs (R\&D Systems, Stillwater, MN, USA), vWF was analysed using validated antibody pairs (DakoCytomation, Oslo, Norway) with a parallel diluted plasma pool as the standard, and ADMA were measured by high-performance liquid chromatography and precolumn derivatization with $o$-phthaldialdehyde (Sigma Chemicals, St. Louis, MO, USA), as described in detail elsewhere with minor modifications ${ }^{21}$. The intra- and interassay coefficients of variation for all measurements were $<10 \%$.

\section{Statistical analysis}

The normality of the variables was assessed by examining histograms. Data are presented as mean $\pm \mathrm{SD}$ or $n(\%)$ values, as appropriate. The independent-samples $t$-test or Fisher's exact test was used as appropriate to assess differences between groups.

The effects of the intervention on coronary physiology indices, health status and biomarkers of endothelial activation in the treatment group compared to the placebo group were assessed using multiple linear regression analyses. The 6-month values were used as the dependent variable according to randomization groups and controlled for preintervention values, and only subjects with paired observations were included in the analysis.

Statistical analyses were performed with IBM SPSS Statistics (version 24, IBM, Armonk, NY, USA). The threshold for statistical significance was set at $p<0.05$, and all tests were twosided. 


\section{RESULTS}

\section{Patient characteristics}

Among the 81 patients invited to participate, 66 patients were randomized into the rosuvastatin and placebo groups. The characteristics of the excluded patients did not differ significantly from those of the included patients (e.g., age, blood work, health status and echocardiographically assessed ejection fraction; data not shown), with the exception of the mean diastolic blood pressure being higher in the non-randomized group (81 $\mathrm{mmHg}$ vs 76 $\mathrm{mmHg}, p=0.01)$. The characteristics of the final study population consisting of 33 patients in each group were well balanced with respect to age, medical history, medications and bloodwork assessments (Table 1). Overall, 10 patients were lost to follow-up (5 in each group): 2 did not take the study drug, 1 declined a second left-heart catheterization and 7 simply did not attend the scheduled follow-up. Apart from the total serum cholesterol level being lower in subjects lost to follow-up, there were no statistically significant differences in baseline characteristics between patients lost to follow-up and patients who completed follow-up (data not shown). The medications taken (angiotensin-converting enzyme inhibitors, angiotensin II receptor blockers, beta-blockers, calcium-channel blockers and aspirin) were comparable between the two study groups both at the baseline and follow-up investigations (Tables 1 and 2). There were no adverse events necessitating withdrawal of the study drugs. Tablet counts at the 6-month follow-up revealed a prescription adherence rate of $>80 \%$ among all patients who completed the 6-month follow-up.

\section{Coronary physiological assessments}

IMR was $14.6(\mathrm{SD} 5.7) \mathrm{mmHg} \cdot \mathrm{s}$ in the placebo group and $16.5(\mathrm{SD} 7.5) \mathrm{mmHg} \cdot \mathrm{s}$ in the rosuvastatin group $(p=0.24)$ at baseline (Table 3 ). Similarly, there were no differences in other 
haemodynamic or coronary physiology measurements and indices at the baseline assessment, except for the mean resting heart rate being higher in the placebo group $(p=0.05)$ (Table 3$)$. Microvascular dysfunction defined as IMR $>20.8 \mathrm{mmHg} \cdot \mathrm{s}$ was observed in $11(17 \%)$ patients at baseline ( 3 and 8 in the placebo and rosuvastatin groups, respectively), with no difference at follow-up (4 and 6 patients, respectively). Similarly, CFR was $<2.5$ in six patients in each group, with no differences between the two groups at follow-up (four and three patients in the rosuvastatin and placebo groups, respectively). At the 6-month follow-up, IMR was 14.4 (SD 6.5) $\mathrm{mmHg} \cdot \mathrm{s}$ in the placebo group and $14.2(\mathrm{SD} \mathrm{5.8)} \mathrm{mmHg} \cdot \mathrm{s}$ in the rosuvastatin group. IMR, FFR, CFR and relevant haemodynamic measures did not differ significantly between the two study groups at follow-up controlled for preintervention values (Table 3).

\section{Health status}

The PCS and MCS scores for SF-36 and the EQVAS and EQ-5D scores at baseline and follow-up for both groups are listed in Table 4. Linear regression analysis of the effect of 6 months of rosuvastatin treatment compared to placebo and controlled for the preintervention assessments revealed no statistically significant differences in health-status scores (Table 4).

Biochemical effects

As expected, the cholesterol levels at the 6-month follow-up were significantly lower in the rosuvastatin group than in the placebo group (Table 3). Importantly, at 6-month follow-up, the CRP levels were also significantly lower in the rosuvastatin group than with placebo (Table 3). In contrast, natriuretic peptides, troponins and markers of endothelial activation (i.e., vWF, sVCAM-1 and ADMA) showed no differences between the placebo and rosuvastatin groups at the follow-up controlled for preintervention values (Table 3).

\section{DISCUSSION}


The key finding of this randomized, double-blinded study of 66 unselected women with chest pain but with no obstructive CAD was that 6 months of high-dose statin treatment did not significantly influence IMR values (Figure 2), health status or markers of endothelial activation. In contrast, the lipid profile was significantly improved, and the CRP levels significantly reduced in the rosuvastatin group. IMR values were comparable to values in a healthy reference population previously reported from our hospital ${ }^{17}$. In total $17 \%$ of the study population had IMR values indicating CMD.

To the best of our knowledge, this is the first double-blind, randomized study to explore the effect of statins on IMR values in women with chest pain and without obstructive CAD. Whereas rosuvastatin showed significant effects on lipid and CRP levels, it showed no effect on IMR, the occurrence of CMD defined as IMR $>20.8 \mathrm{mmHg} \cdot \mathrm{s}$ or markers of endothelial activation (Figure 3). The effects of statins on CMD have previously been studied in various settings but comparing the results of the present study with those of previous studies is difficult due to the small number of studies and the differences in end points and study designs. A study of the acute effect of atorvastatin showed a significant increase in the transthoracic Doppler-derived CFR in the atorvastatin group compared to no change in the placebo group ${ }^{8}$. The effect of statins on the Doppler-derived CFR was studied in 20 patients with angiographically slow coronary flow (20 mg of atorvastatin daily for 8 months) ${ }^{13}$ and in 56 hypertensive patients ( $10 \mathrm{mg}$ of rosuvastatin daily for 12 months $)^{22}$, with both studies showing significant increases in CFR. However, these were not placebo-controlled studies, which may explain the divergent results compared to the current study.

A positive effect of statin treatment on endothelium-dependent vasodilatation as assessed by flow-mediated dilatation in the peripheral arteries has been demonstrated in studies of women with syndrome $\mathrm{X}^{23-25}$. However, it might not be valid to extrapolate these findings to the current study since adenosine primarily assesses endothelium-independent vasodilatation, and 
the effects on the peripheral vessels may differ from those on the cardiac vasculature. Previous studies of the effects of statins administered prior to percutaneous coronary interventions indicate that statin pretreatment is beneficial to the IMR ${ }^{26,27}$; however, the relevance of this finding to the current study is disputable, since epicardial CAD was an exclusion criterion.

Experimental studies have suggested that statins can exert endothelium-independent vasodilatation effects ${ }^{28,29}$, but clinical studies involving humans have been lacking. Our findings do not unambiguously support an endothelium-independent effect of rosuvastatin, since there was no statistically significant decrease in IMR after 6 months. Moreover, although rosuvastatin down-regulated the lipid and CRP levels, it did not affect markers of endothelial activation. However, reduction of CRP is prognostically important as shown among others in the Jupiter trial ${ }^{9,11}$. The short follow-up period in this study may explain lacking improvements in other outcome measures. Previous reviews have found conflicting effects of statins on ADMA, sVCAM-1 and $\mathrm{vWF}^{30-33}$. A possible explanation that needs to be investigated further is that such effects would require pre-existing hypercholesterolaemia, which was not present in the current study. Moreover, different statins might exert different effects. It is also possible that patients with residual inflammation could specifically benefit from such a therapy.

Both the SF-36 and EQ-5D scores in the present study were comparable to those found in previous studies of patients with stable angina or CAD ${ }^{34-37}$. The extent to which the sensitivity of generic health-status instruments is comparable to that of disease-specific questionnaires such as the Seattle Angina Questionnaire (SAQ) and Canadian Cardiovascular Society Angina Classification (CCS) has been questioned ${ }^{35}$. This correspondence may differ between patient populations and types of intervention. Furthermore, non-significant changes in SF-36 and EQ-5D scores are consistent with the lack of significant improvements in 
microvascular function as assessed with IMR. In contrast, a previous study found that combination therapy with atorvastatin and ramipril improved the health status of women with microvascular angina, as assessed with the SAQ ${ }^{25}$. We did not report the CCS class due to difficulties of classifying patients with atypical angina.

\section{Study limitations}

The current pilot study was designed to evaluate the effects of rosuvastatin on IMR, health status and markers of endothelial activation. The randomization was skewed in terms of the IMR distribution between the two randomization groups: the mean IMR was $1.9 \mathrm{mmHg} \cdot \mathrm{s}$ higher in the treatment group than in the placebo group at baseline, and the decrease of 2.3 $\mathrm{mmHg} \cdot \mathrm{s}$ in the former compared to $0.2 \mathrm{mmHg} \cdot \mathrm{s}$ in the latter did not reach statistical significance. The decrease may be attributed to a "regression to the mean" effect. In addition, the relatively small sample size of the study is a major limitation, which implies a risk of type II errors. Hence, the study power was insufficient for detecting a possible effect of rosuvastatin on IMR. In addition, the number of subjects lost to follow up, further weakens the statistical power. Based on the inclusion criteria, the study was not powered to see if women with CMD could represent a subgroup that will benefit from statin therapy. On the other hand, a major strength of the study is the repeated invasive assessment with paired analyses within subjects.

\section{CONCLUSIONS}

Rosuvastatin treatment for 6 months did not improve the health status, endothelial activation or microvascular function as assessed with the IMR method. However, caution is needed when interpreting these results due to skewness of the IMR at randomization and the smallness of the sample, leading to the possibility of type II errors. The study was not 
restricted to women with microvascular dysfunction (i.e., IMR $>20.8 \mathrm{mmHg}$ ), and

forthcoming studies should examine if these women could have an effect of statin

intervention.

Reference List

(1) Quyyumi AA. Women and ischemic heart disease: pathophysiologic implications from the Women's Ischemia Syndrome Evaluation (WISE) Study and future research steps. J Am Coll Cardiol 2006;47:S66-S71.

(2) Jespersen L, Hvelplund A, Abildstrom SZ, Pedersen F, Galatius S, Madsen JK, Jorgensen E, Kelbaek $\mathrm{H}$, Prescott E. Stable angina pectoris with no obstructive coronary artery disease is associated with increased risks of major adverse cardiovascular events. Eur Heart J 2012;33:734-44.

(3) Johnson BD, Shaw LJ, Pepine CJ, Reis SE, Kelsey SF, Sopko G, Rogers WJ, Mankad S, Sharaf BL, Bittner V, Bairey Merz CN. Persistent chest pain predicts cardiovascular events in women without obstructive coronary artery disease: results from the NIH-NHLBI-sponsored Women's Ischaemia Syndrome Evaluation (WISE) study. Eur Heart J 2006;27:1408-15.

(4) Atienza F, Velasco JA, Brown S, Ridocci F, Kaski JC. Assessment of quality of life in patients with chest pain and normal coronary arteriogram (syndrome X) using a specific questionnaire. Clin Cardiol 1999;22:283-90.

(5) Olson MB, Kelsey SF, Matthews K, Shaw LJ, Sharaf BL, Pohost GM, Cornell CE, McGorray SP, Vido D, Bairey Merz CN. Symptoms, myocardial ischaemia and quality of life in women: results from the NHLBI-sponsored WISE Study. Eur Heart J 2003;24:1506-14.

(6) Pepine CJ, Ferdinand KC, Shaw LJ, Light-McGroary KA, Shah RU, Gulati M, Duvernoy C, Walsh MN, Bairey Merz CN. Emergence of Nonobstructive Coronary Artery Disease: A Woman's Problem and Need for Change in Definition on Angiography. J Am Coll Cardiol 2015;66:1918-33.

(7) Undas A, Brummel-Ziedins KE, Mann KG. Statins and blood coagulation. Arterioscler Thromb Vasc Biol 2005;25:287-94.

(8) Hinoi T, Matsuo S, Tadehara F, Tsujiyama S, Yamakido M. Acute effect of atorvastatin on coronary circulation measured by transthoracic Doppler echocardiography in patients without coronary artery disease by angiography. Am J Cardiol 2005;96:89-91.

(9) Ridker PM, Danielson E, Fonseca FA, Genest J, Gotto AM, Jr., Kastelein JJ, Koenig W, Libby P, Lorenzatti AJ, MacFadyen JG, Nordestgaard BG, Shepherd J, Willerson JT, Glynn RJ. Reduction in Creactive protein and LDL cholesterol and cardiovascular event rates after initiation of rosuvastatin: a prospective study of the JUPITER trial. Lancet 2009;373:1175-82.

(10) Maron DJ, Fazio S, Linton MF. Current perspectives on statins. Circulation 2000;101:207-13.

(11) Ridker PM, MacFadyen J, Libby P, Glynn RJ. Relation of baseline high-sensitivity C-reactive protein level to cardiovascular outcomes with rosuvastatin in the Justification for Use of statins in Prevention: an Intervention Trial Evaluating Rosuvastatin (JUPITER). Am J Cardiol 2010;106:204-9.

(12) Zhang X, Li Q, Zhao J, Li X, Sun X, Yang H, Wu Z, Yang J. Effects of combination of statin and calcium channel blocker in patients with cardiac syndrome X. Coron Artery Dis 2014;25:40-4. 
(13) Caliskan M, Erdogan D, Gullu H, Topcu S, Ciftci O, Yildirir A, Muderrisoglu H. Effects of atorvastatin on coronary flow reserve in patients with slow coronary flow. Clin Cardiol 2007;30:475-9.

(14) Palinski W. New evidence for beneficial effects of statins unrelated to lipid lowering. Arterioscler Thromb Vasc Biol 2001;21:3-5.

(15) Fearon WF, Balsam LB, Farouque HM, Caffarelli AD, Robbins RC, Fitzgerald PJ, Yock PG, Yeung AC. Novel index for invasively assessing the coronary microcirculation. Circulation 2003;107:3129-32.

(16) Lang RM, Badano LP, Mor-Avi V, Afilalo J, Armstrong A, Ernande L, Flachskampf FA, Foster E, Goldstein SA, Kuznetsova T, Lancellotti P, Muraru D, Picard MH, Rietzschel ER, Rudski L, Spencer KT, Tsang W, Voigt JU. Recommendations for cardiac chamber quantification by echocardiography in adults: an update from the American Society of Echocardiography and the European Association of Cardiovascular Imaging. J Am Soc Echocardiogr 2015;28:1-39.

(17) Solberg OG, Ragnarsson A, Kvarsnes A, Endresen K, Kongsgard E, Aakhus S, Gullestad L, Stavem K, Aaberge L. Reference interval for the index of coronary microvascular resistance. EuroIntervention 2014;9:1069-75.

(18) Ware JE, Jr., Sherbourne CD. The MOS 36-item short-form health survey (SF-36). I. Conceptual framework and item selection. Med Care 1992;30:473-83.

(19) EuroQol--a new facility for the measurement of health-related quality of life. Health Policy 1990;16:199-208.

(20) Dolan P. Modeling valuations for EuroQol health states. Med Care 1997;35:1095-108.

(21) Eid HM, Eritsland J, Larsen J, Arnesen H, Seljeflot I. Increased levels of asymmetric dimethylarginine in populations at risk for atherosclerotic disease. Effects of pravastatin. Atherosclerosis 2003;166:27984.

(22) Sun BJ, Hwang E, Jang JY, Kim DH, Song JM, Kang DH. Effect of rosuvastatin on coronary flow reserve in patients with systemic hypertension. Am J Cardiol 2014;114:1234-7.

(23) Kayikcioglu M, Payzin S, Yavuzgil O, Kultursay H, Can LH, Soydan I. Benefits of statin treatment in cardiac syndrome-X1. Eur Heart J 2003;24:1999-2005.

(24) Fabian E, Varga A, Picano E, Vajo Z, Ronaszeki A, Csanady M. Effect of simvastatin on endothelial function in cardiac syndrome X patients. Am J Cardiol 2004;94:652-5.

(25) Pizzi C, Manfrini O, Fontana F, Bugiardini R. Angiotensin-converting enzyme inhibitors and 3hydroxy-3-methylglutaryl coenzyme A reductase in cardiac Syndrome X: role of superoxide dismutase activity. Circulation 2004;109:53-8.

(26) Fujii K, Kawasaki D, Oka K, Akahori H, Iwasaku T, Fukunaga M, Eguchi A, Sawada H, Masutani M, Lee-Kawabata M, Tsujino T, Ohyanagi M, Masuyama T. The impact of pravastatin pre-treatment on periprocedural microcirculatory damage in patients undergoing percutaneous coronary intervention. JACC Cardiovasc Interv 2011;4:513-20.

(27) Lee BK, Koo BK, Nam CW, Doh JH, Chung WY, Cho BR, Fearon WF. Does Pre-Treatment with High Dose Atorvastatin Prevent Microvascular Dysfunction after Percutaneous Coronary Intervention in Patients with Acute Coronary Syndrome? Korean Circ J 2016;46:472-80.

(28) Lorkowska B, Chlopicki S. Statins as coronary vasodilators in isolated bovine coronary arteries-involvement of PGI2 and NO. Prostaglandins Leukot Essent Fatty Acids 2005;72:133-8.

(29) McGowan CL, Murai H, Millar PJ, Notarius CF, Morris BL, Floras JS. Simvastatin reduces sympathetic outflow and augments endothelium-independent dilation in non-hyperlipidaemic primary hypertension. Heart 2013;99:240-6. 
(30) Sibal L, Agarwal SC, Home PD, Boger RH. The Role of Asymmetric Dimethylarginine (ADMA) in Endothelial Dysfunction and Cardiovascular Disease. Curr Cardiol Rev 2010;6:82-90.

(31) Greenwood J, Mason JC. Statins and the vascular endothelial inflammatory response. Trends Immunol 2007;28:88-98.

(32) Davignon J. Beneficial cardiovascular pleiotropic effects of statins. Circulation 2004;109:III39-III43.

(33) Sahebkar A, Serban C, Ursoniu S, Mikhailidis DP, Undas A, Lip GY, Bittner V, Ray K, Watts GF, Hovingh GK, Rysz J, Kastelein JJ, Banach M. The impact of statin therapy on plasma levels of von Willebrand factor antigen. Systematic review and meta-analysis of randomised placebo-controlled trials. Thromb Haemost 2016;115:520-32.

(34) Wijeysundera HC, Farshchi-Zarabi S, Witteman W, Bennell MC. Conversion of the Seattle Angina Questionnaire into EQ-5D utilities for ischemic heart disease: a systematic review and catalog of the literature. Clinicoecon Outcomes Res 2014;6:253-68.

(35) Dougherty CM, Dewhurst T, Nichol WP, Spertus J. Comparison of three quality of life instruments in stable angina pectoris: Seattle Angina Questionnaire, Short Form Health Survey (SF-36), and Quality of Life Index-Cardiac Version III. J Clin Epidemiol 1998;51:569-75.

(36) Spertus JA, Winder JA, Dewhurst TA, Deyo RA, Fihn SD. Monitoring the quality of life in patients with coronary artery disease. Am J Cardiol 1994;74:1240-4.

(37) Wu J, Han Y, Xu J, Lu Y, Cong H, Zheng J, Sun H. Chronic stable angina is associated with lower health-related quality of life: evidence from Chinese patients. PLoS One 2014;9:e97294.

Figure legends

Figure 1.

Patient flow chart. CAD, coronary artery disease; FU, follow-up.

Figure 2.

Effect of rosuvastatin on IMR at baseline and 6-month follow-up compared to placebo, mean values \pm SD. $p=0.55$ for IMR at 6 -month follow-up in the rosuvastatin group compared to the placebo group controlled for preintervention values (multiple linear regression).

Figure 3. 
In addition to improvement of lipid profile, statins exhibit anti-inflammatory effects known to inhibit progression and development of epicardial coronary artery disease. Despite significant decrease of total cholesterol, LDL-cholesterol and CRP; coronary microvascular function as assessed with IMR was not significantly improved. 